\title{
ADVANCEMENT OF SOLAR SELECTIVE DLC COATING USING CAPVD FOR SOLAR THERMAL APPLICATIONS
}

\author{
Ambati Sandeep ${ }^{1, \star}$, K. Archana ${ }^{1}$, Sivakumar Ellappan ${ }^{1}$, Dandu Mallesham $^{1}$
}

\begin{abstract}
Metal nitride multilayer films display a unique combination of exceptional properties with respect to optical absorption, thermal emission, corrosion resistance, adhesion between coating and surface and high temperature withstand. Most considerable aspects of nitride coatings were economical, environmentally friendly and easy to develop. Similar to nitride thin films, to achieve a considerable absorption $(\alpha)-0.92$ and low emission $(\mathcal{C})$ 0.08 along with chemical and radiation stable solar selective coatings, Diamond Like Carbon (DLC) thin films exhibit the desirable properties for Concentrated Solar thermal Power(CSP)applications. The main advantages of DLC films were high hardness, chemical and radiation stability and good control over the optical properties. To achieve above-mentioned properties, optimization of each layer of the DLC coating has needed. The main aim of this research is optimization of Cr-base layer using Cr-Target current 175A to get $125 \mathrm{~nm}$ thicknesses, optimise the AlSiN absorber layer by controlling the AlSi- target current 175A to maintain 35nm thickness. The sequence of the DLC coating layers was selected based on their relative thickness, which was optimize to get good solar selectivity $(\alpha / \epsilon)$. Individual layers of the DLC solar coatings have unique properties to get overall required high absorbance and low emission along with chemical and radiation stability. These solar selective multi-layers (Cr/DLC/AlSiN) have deposited by using available Cathodic targets (Cr , AlSi \& Ti) in Cathodic Arc Physical Vapor Deposition (CAPVD) and optimized parameters were mainly depend on the target currents to control over the thickness of the each layer, base pressure $1^{*} 10^{-5}$ mbar and deposition temperature $400^{\circ} \mathrm{C}$. The DLC multilayer solar selective coatings were characterized using Ultraviolet Visible Near infrared (UV- Vis- NIR) spectrophotometer, Scanning Electronic Microscopy (SEM), Transmission Electron Microscopy (TEM) and Raman spectroscopy etc. Scratch test and corrosion tests have conducted for these absorber coatings testing.
\end{abstract}

Keywords: DLC Multilayer Absorber Coating, Solar-Irradiation, Radiation Stable, High Hardness

\section{INTRODUCTION}

\section{Metal Nitride Multilayer Absorbers}

In recent years, solar energy utilization has increased. It is an eco-friendly and non-polluting idea that converts the everlasting solar radiation into thermal energy/electrical energy used to fulfill the increasing demand of

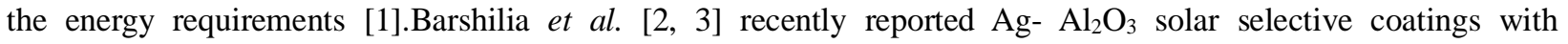
absorbance and emission of $0.93,0.04-0.05$ respectively at $82^{\circ} \mathrm{C}$ in the IR region. However most of these coatings suffers from poor oxidation resistance $\left(>135^{\circ} \mathrm{C}\right)$ [4] and contains water inclusions resulting in lower life-time due to continuous exposure to sun light. Yin et al. [5] in his studies related to $\mathrm{Cr}$ based absorbers reported $\mathrm{Cr}_{-}-\mathrm{Cr}_{2} \mathrm{O}_{3}$ cermet solar selective coatings. For these coatings, an absorbance of 0.92- 0.96 and thermal emittance $0.05-0.08$ was observed with thermally stability up to $300-400^{\circ}$ C. In this present study, an attempt has made to develop a highly efficient solar thermal conversion system. The effective conversion of solar energy into thermal energy is possible only using proper absorber materials. Depending upon the physical nature of the absorber material, they were classified into several categories [6]. Among all the above absorbers, thin films (can be mono or multilayer) with their excellent tailor-made optical properties are widely used as solar selective coatings [7]. There were many attempts only to maximize „, $\alpha^{\text {ee }}$ and minimize „, $\mathcal{C}^{\mathrm{ee}}$ to achieve a high selectivity $(\alpha / \epsilon)[8,9]$. In concentrated solar power plant (CSP) the efficiency and thermal heat, distribution depends up on the working fluid, which passes through the solar absorber tube. [10] Reported that Nano-fluid with 0.625 g/lit. Concentration of led $(\mathrm{Pb})$ gives the

This paper was recommended for publication in revised form by Regional Editor Hasan Köten

${ }^{1}$ MLR Institute of Technology, Hyderabad, India, 500043

*E-mail address: sandeepambati76@gmail.com

Orcid id: 0000-0002-4006-9884, 0000-0002-5028-0093, 0000-0003-4328-3410, 0000-0002-8569-5619

Manuscript Received 20 August 2019, Accepted 27 October 2019 
best thermal performance. There are many ways of growing solar selective thin films. The two major techniques are chemical and physical process. [11] Increasing of Led $(\mathrm{Pb})$ concentration in Nano-fluid, it affects the increase of wall shear stress due to dynamic viscosity increases. [12] Reported that Led (Pb)-selenite Nano-fluid have the better performance because when solar absorber tube exposed to sun energy, the photons directly hit the Nano- fluid, it releases the electrons and so by suing this Nano-fluid, we can produce more energy. [13] Reported that heat transfer rate and thermal conductivity of the Nano-fluid mainly depends up on the size of the Nano-fluid particle. [14] Due to having large surface area and large number cavities, Carbon Nano horns (CNHs) Nano-fluid has the best performance due to it improves the optical properties of the direct solar collector. [15] To increase the efficiency of Heat Pipe Solar Collector (HPC), need to add more than one mixture of Nano-fluid. There are several physical processes based on vacuum processes like sputtering, cathodic arc deposition etc. In addition to the above factors, the advanced receiver technology demands coatings that are stable up to $600^{\circ} \mathrm{C}$. From literature, these high end applications can be easily addressed with PVD developed solar absorber coatings. In general, so far, most of the reported absorber materials are metal oxides [16-21] and there are very few nitrides [22]. The same group has also reported TiAlN/TiAlON/Si $\mathrm{N}_{4}$ absorber grown using magnetron sputtering. These absorbers were reported to be air stable up to $600^{\circ} \mathrm{C}$ with absorbance of 0.95 and emission 0.07 . The above given table: 1 clearly shows that literature survey regarding the solar coatings with selection of the best solar layers by using different types of coating techniques. The common point in all these studies being, trying to achieve good absorbance and low emission values but some researchers tried to get high absorbance along with good hardness

Table 1. Reference list

\begin{tabular}{|l|l|l|l|l|l|}
\hline S.NO. & COATING/SUBSTRATE & TECHNIQUE & $(\boldsymbol{\alpha})$ & $(\mathbf{G})$ & REFERENCES \\
\hline $\mathbf{1}$ & Black Mo on SS & CVD & 0.74 & 0.08 & {$[27]$} \\
\hline $\mathbf{2}$ & Black Ni on Zinc & Electroplating & 0.94 & 0.10 & {$[28]$} \\
\hline $\mathbf{3}$ & Black Ni on Zincated Al & Electroplating & 0.90 & 0.14 & {$[28]$} \\
\hline $\mathbf{4}$ & Black chrome on steel & Electroplating & 0.868 & 0.088 & {$[29]$} \\
\hline $\mathbf{5}$ & Chrome black on Cu & Chromox & 0.87 & 0.03 & {$[30]$} \\
\hline $\mathbf{6}$ & Co3O4 on Cu & Plating & 0.93 & 0.24 & {$[31]$} \\
\hline $\mathbf{7}$ & TiAlN on Cu & DC Sputtering & 0.80 & $014-0.40$ & {$[32]$} \\
\hline $\mathbf{8}$ & TiNx or ZrNx on SS & $\begin{array}{l}\text { Vacuum } \\
\text { Sputtering }\end{array}$ & $0.88-$ & $0.04-0.19$ & {$[33]$} \\
\hline $\mathbf{9}$ & $\begin{array}{l}\text { Black Co on Galvanized } \\
\text { Fe }\end{array}$ & Spray Pyrolysis & 0.91 & 0.12 & {$[34]$} \\
\hline $\mathbf{1 0}$ & Black Co on Al & Spray Pyrolysis & 0.92 & 0.13 & {$[34]$} \\
\hline $\mathbf{1 1}$ & Mo-Al2O3 on Cu & DC Sputtering & 0.96 & 0.06 & {$[32]$} \\
\hline $\mathbf{1 2}$ & $\begin{array}{l}\text { MgO / Au cermet film on } \\
\text { SS }\end{array}$ & RF Sputtering & 0.90 & 0.10 & {$[35]$} \\
\hline $\mathbf{1 3}$ & $\begin{array}{l}\text { Al2O3 / Mo / Al2O3 on } \\
\text { Mo }\end{array}$ & Evaporation & 0.85 & 0.22 & {$[36]$} \\
\hline $\mathbf{1 4}$ & TiO2/Ag/TiO2 on SS & RF Sputtering & 0.54 & 0.01 & {$[37]$} \\
\hline $\mathbf{1 5}$ & $\begin{array}{l}\text { Al2O3/Mo/Al2O3/Mo/Al } \\
\mathbf{2 O 3} \text { on Mo }\end{array}$ & Evaporation & 0.91 & 0.085 & {$[38]$} \\
\hline
\end{tabular}




\section{Diamond Like Carbon (DLC) Absorbers}

DLC is inferior to diamond in many respects; the ability to deposit a very smooth DLC film on any solid substrate opens a much broad range of applications. With the noticed advantages of DLC coatings, these coatings were reported to be widely useful in solar applications. Klyui et al. [23] reported that DLC antireflective coatings improve the solar cell efficiency 1.35- 1.5 times. Tinchev et al. [24] attempted to use DLC coatings for solar absorber application (the tunability of optical band gap in DLC is possible by varying deposition conditions and process). Gampp et al. [25] developed the Cr- contained amorphous carbon coatings and achieved the highest absorbance $91.8 \%$ and emission of $8.6 \%$ these coatings showed a minimum service lifetime of 25 years under standard conditions. Tinchev et al. [26] achieved the maximum solar absorbance of 92\% in DLC solar absorbers. Most of the researchers used DLC coatings in photovoltaic applications; very few reports were available on solar thermal applications. Hence, in the present work an attempt has been made to translate the advantages of CAD for growing advanced nitride absorber coatings as well as DLC based solar selective coatings.

\section{EXPERIMENTAL PROCEDURE Thin Film Deposition}

Aluminium (Al), chromium (Cr), Titanium (Ti) and Silicon (Si) based nitrides and oxides are widely used in various types of solar absorber coatings due to properties like high solar absorbance and low IR emission with high thermal stability and corrosion resistance. In this particular study an attempt was made to develop a novel solar selective multi-layer coating comprising of TiAlN, TiAlCrN, AlSiN and Diamond Like carbon (DLC) materials over different substrates like Copper (Cu), 316 Stainless Steel (SS), Silica Carbide (SiC) using Cathodic Arc Physical Vapour Deposition process.

\section{Substrate Preparation}

Prior to the thin film deposition, the polished substrates with dimensions $60 \times 60 \times 3 \mathrm{~mm}^{3}$ were cleaned and conditioned thoroughly through a series of processes. It eliminates all the surface contaminants (dirt, grease and other foreign particles) to induce metallurgical bond, which is needed during the further processes. The substrate conditioning involves series of steps: chemical cleaning and argon etching followed by ion bombardment (in the deposition chamber).

\section{Thin Film Deposition Process}

The thin film deposition was carried out using Cathodic Arc Deposition (CAD) facility (fig.1). It was a compact medium size coating unit with cylindrical cathodes and is capable of depositing a variety of coatings. The maximum achievable base pressure prior to the coating was $1 \times 10^{-7}$ mbar. It consisted of 4 different cathodes namely $\mathrm{Ti}, \mathrm{Al}-\mathrm{Si}, \mathrm{Cr}$ and $\mathrm{Al}-\mathrm{Ti}$ around a carousel (with the possibility of rotating in a planetary motion) in a double-walled stainless steel chamber (the cathodes can be changed depending on the requirement). The whole deposition process can be controlled manually or automatically operated through a computer.

Prior to the development of multilayer absorber coatings, the possible constituents of multi-layer structure are identified by growing different possible metallic and nitride coatings on copper substrate. The deposition parameters are pressure $-2 \times 10^{-2}$ mbar, negative bias $-50 \mathrm{~V}$ and thickness $-90 \mathrm{~nm}$. Subsequently all the coatings were subjected to absorbance and emission measurements. From the results TiAlCrN, TiAlN and DLC are identified as the best absorber materials. Therefore, all the further experiments are restricted to the multi layers of TiAlCrN, TiAlN and DLC only. 


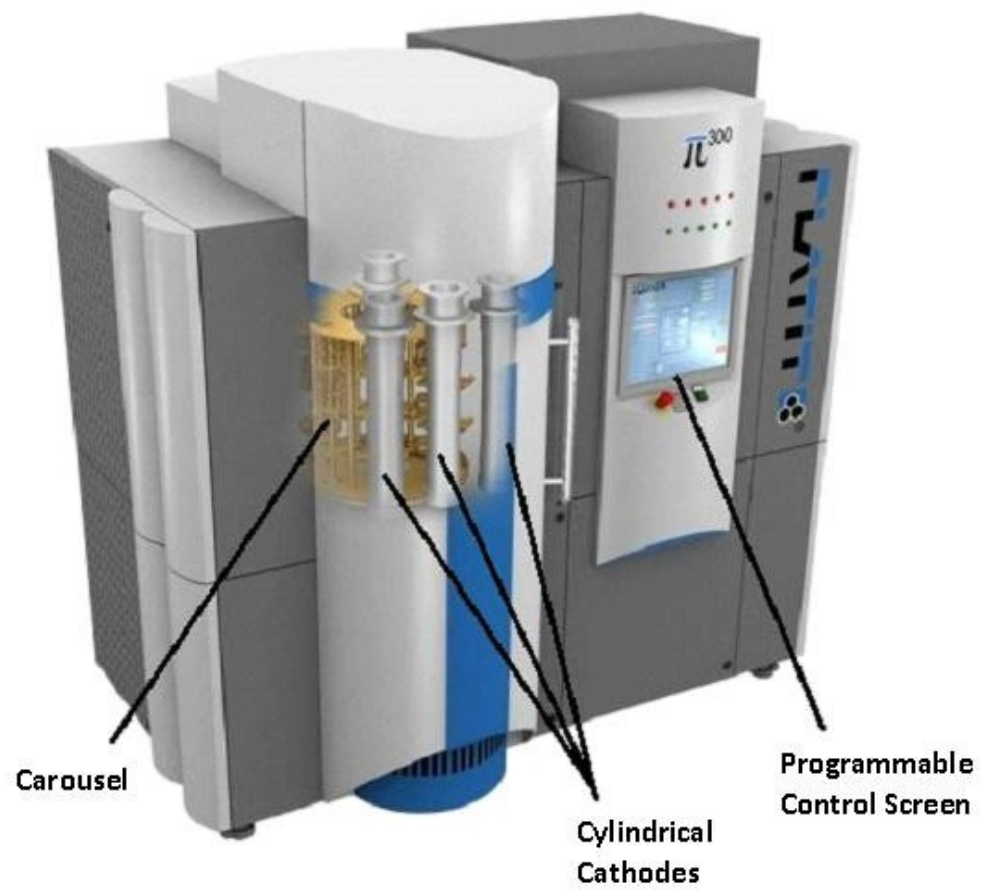

Figure 1. Cathodic physical vapour deposition

\section{(Cr/DLCIAISiN) Coating}

DLC solar selective absorber coatings have been developed initially with $85 \mathrm{~A} \mathrm{Cr}$ - current at $1.8 \times 10^{-2} \mathrm{mbar}$ pressure to obtain $200 \mathrm{~nm}$ thicknesses. The developed coatings were studied for their absorption and emission properties. After this initial study, the coatings were generated with varying Cr- cathode currents (the range 85-175 A). During this process, the coating thickness was maintained constant. The same procedure was followed for other cathode materials also. Out of all the DLC coatings (deposited using different cathode materials), the best optimized DLC coating was obtained at $85 \mathrm{~A} \mathrm{Cr}$-current with $90 \mathrm{~nm}$ thickness. The optimized pressure and substrate bias were around $1.8 \times 10^{-2}$ mbar and $50 \mathrm{~V}$ respectively. The optimized absorber DLC has $0.84 \%$ absorption, $0.03 \%$ emissions to improve the absorption further, multilayer coatings with different possible combinations of DLC with metal and metal nitride coatings have been deposited. Out of all the combinations, Cr/DLC/AlSiN coating sequence has the best properties like $0.92 \%$ absorption and $0.08 \%$ emission. All these coatings were grown at fixed temperature $400^{\circ}$ $\mathrm{C}$, deposition pressure of $1.8 \times 10^{-2}$ mbar (in this case $\mathrm{C}_{2} \mathrm{H}_{2}$ gas is the source for carbon). Further, with the optimized DLC thickness and composition, multi-layer absorber coating is developed. After the initial studies, $\mathrm{Cr} / \mathrm{DLC} / \mathrm{AlSiN}$ was found to exhibit highest absorption and low thermal emission. DLC deposition temperature $\left(275-425^{\circ} \mathrm{C}\right)$ was also optimized by keep the other optimized parameters fixed.

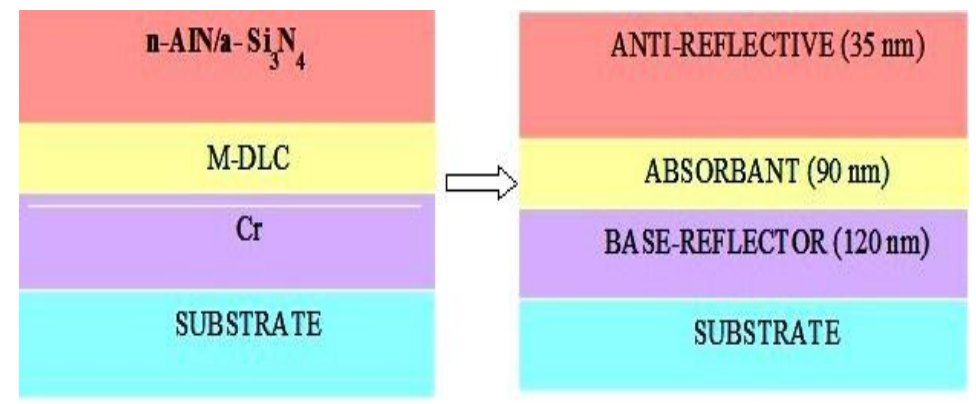

Figure 2. Schematic of DLC contained multilayer absorber 
Table 2. Deposition parameters

\begin{tabular}{|l|l|l|}
\hline S.NO. & Experimental Conditions & Values \\
\hline $\mathbf{1}$ & Substrate & SS 304 \\
\hline $\mathbf{2}$ & Cathode materials & $\mathrm{Cr}, \mathrm{AlSi} \& \mathrm{AlTi}$ \\
\hline $\mathbf{3}$ & Process gases & $\mathrm{N}_{2}, \mathrm{Ar} \& \mathrm{C}_{2} \mathrm{H}_{2}$ \\
\hline $\mathbf{4}$ & Cathode to substrate distance & $6.0 \mathrm{~cm}$ \\
\hline $\mathbf{5}$ & Substrate rotation & $6 \mathrm{RPM}$ \\
\hline $\mathbf{6}$ & Cr cathode current & $175 \mathrm{~A}$ \\
\hline $\mathbf{7}$ & AlSi cathode current & $150 \mathrm{~A}$ \\
\hline $\mathbf{8}$ & AlTi cathode current & $250 \mathrm{~A}$ \\
\hline $\mathbf{9}$ & Base vacuum & $1 * 10^{-5}$ \\
\hline $\mathbf{1 0}$ & Working pressure & $1.8^{*} 10^{-2}$ mbar \\
\hline $\mathbf{1 1}$ & Temperature & $400^{\circ} \mathrm{C}$ \\
\hline $\mathbf{1 2}$ & Cr-Current (A) Range & $85-175 \mathrm{~A}$ \\
\hline $\mathbf{1 3}$ & C $\mathrm{H}_{2}$-flow & Pressure constant $(95 \mathrm{sccm})$ \\
\hline $\mathbf{1 4}$ & Bias Voltage & $-50 \mathrm{~V}$ \\
\hline $\mathbf{1 5}$ & Mode of operation & DC Mode \\
\hline $\mathbf{1 6}$ & Substrate Current (A) & $1.2 \mathrm{~A}$ \\
\hline
\end{tabular}

The schematic of the optimized three-layer absorber coating is shown in Fig. 2. In this multilayer coating, pure $\mathrm{Cr}$ metal layer is supposed to act like a reflective coating and metal doped diamond like carbon (DLC) acts as absorber. The top Nano-composite AlSiN layer act as an antireflective layer and it helps in improving the absorption. The optimized coating parameters (as shown in table: 2) for the development of highly efficient DLC multilayer solar absorber coating were selected based on results obtained by varying the target currents (Cr: 85-175 A), coating thickness and deposition pressure.

\section{UNCERTAINTY ANALYSYS}

\section{Identification of Absorber Materia}

Initially, developed all possible coatings using the available cathodes in CAPVD (PLATIT $\pi^{300}$ ) coating equipment and studied for their absorption properties. From the absorption data, identified all the possible absorber materials for multilayer structure. In this part of the work, identification of the best absorber material that could be formed using available cathodes in the CAPVD like Ti, Cr, AlSi and TiAl was done using constant deposition parameters like; Nitrogen partial pressure, thickness, substrate temperature, substrate bias. The optical absorbance $(300-2500 \mathrm{~nm})$ and thermal emission $(2.5-50 \mu \mathrm{m})$ were measured (Table 3) from these material combination. Reflectance spectra of different possible nitride films are shown in Fig. 3. 
Table 3. Absorption values of different substrates, metals and metal nitride films

\begin{tabular}{|l|l|l|l|l|}
\hline S. NO. & Coating & Substrate & Absorption( $\boldsymbol{\alpha})$ & Emission(c) \\
\hline $\mathbf{1}$ & TiAlCrN/TiAlN/AlSiN & $\mathbf{C u}$ & $\mathbf{0 . 9 2}$ & $\mathbf{0 . 0 8}$ \\
\hline & & SS & 0.92 & 0.18 \\
\hline & & SiC & $0.93-0.95$ & 0.64 \\
\hline $\mathbf{2}$ & Cr/TiAlN/AlSiN & SS & $\mathbf{0 . 8 8 - 0 . 9 0}$ & $\mathbf{0 . 0 7 - 0 . 1 3}$ \\
\hline & & $\mathrm{Cu}$ & 0.90 & 0.08 \\
\hline & & SiC & 0.91 & 0.53 \\
\hline $\mathbf{3}$ & Cr/TiAlCrN/TiAlN/AlSiN & SiC & $\mathbf{0 . 9 1}$ & $\mathbf{0 . 1 8}$ \\
\hline $\mathbf{4}$ & Cr/DLC/AlSiN & $\mathrm{Cu}$ & 0.92 & 0.08 \\
\hline & & $\mathrm{SS}$ & 0.92 & 0.08 \\
\hline
\end{tabular}

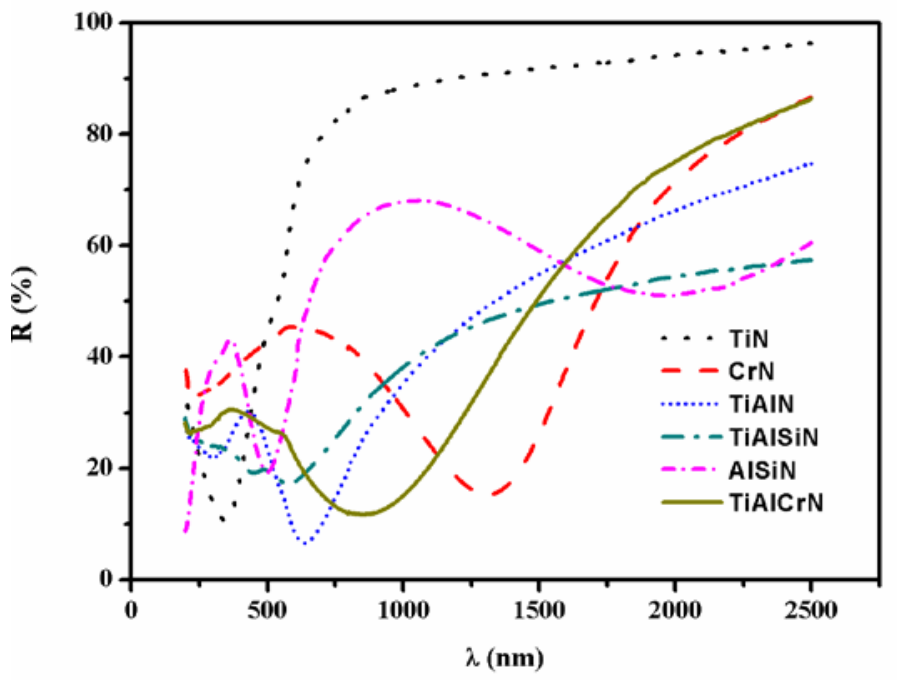

Figure 3. Reflectance spectra of different possible material combinations

From these results, it was observed that, the films with maximum $\mathrm{Cr}$ content have maximum absorbance followed by those with TiAlN (Al rich). Hence, the solar absorber coating was selected such that it should contain the $\mathrm{Cr}$ rich nitride and TiAlN layers as absorbers. In addition to absorber layer selection, antireflective coating selection also has been done by growing different nitrides on the identified absorber coating. Out of all possible nitrides, AlSiN coating has shown better results. Hence in all further studies AlSiN has been taken as antireflective coating. After identification of proper absorber materials they were stacked in different ways to identify the best combination. The number of layers required is also optimized. From the results, the multilayer with three-layer structure has shown best optical properties.

\section{OPTIMIZATION STUDIES FOR ACHIEVING HIGH SOLAR SELECTIVITY}

Selection of constituent layers in a multilayer structure has been carried out by growing different combinations (different nitrides) of multi-layer structures. Optimization of thickness of individual layers: Theoretically chosen the thickness in order to create destructive interference and validated the same experimentally. Elemental composition of each layer was optimized to get high absorption and low emission. $\mathrm{N}_{2}$ reactive gas partial pressure and substrate bias also optimized. DLC based multilayer coating has been developed for obtaining same 
properties on both the $\mathrm{Cu}$ and SS steel substrates and achieved highest absorption and lowest emission are $92 \%$ and $8 \%$.

\section{RESULTS AND DISCUSSION Substrate Effect}

In these DLC multilayer observer coatings, substrate type was also found to have a major role in deciding solar absorbance and emission. In order to suppress the substrate effect, a thick (125 nm) Cr layer is initially deposited on SS 304 and then the optimized multilayer absorber coating is developed. With the inclusion of Cr layer, the DLC absorber coating has shown similar optical properties on any substrate. The reflectance spectra of DLC absorber coating on different substrates is shown in Fig.4. In the below given fig. 4. SiC substrate has given good absorbance value and low emission along with high thermal distribution throughout the absorber tube over the wavelength ( 300 to $2500 \mathrm{~nm}$ visible region ), but only problem with this, it is very low mechanical strength as compared to SS and Cu substrates. Cu is also performing almost as same as SiC Substrate according to absorption values, but here also $\mathrm{Cu}$ is less mechanical strength as compare to SS, so finally we found that SS-tube is the optimized substrate for DLC multilayer solar absorber coatings. Selection of substrate by considering absorbance, emission and mechanical strength is $\mathrm{SS}>\mathrm{Cu}>\mathrm{SiC}$

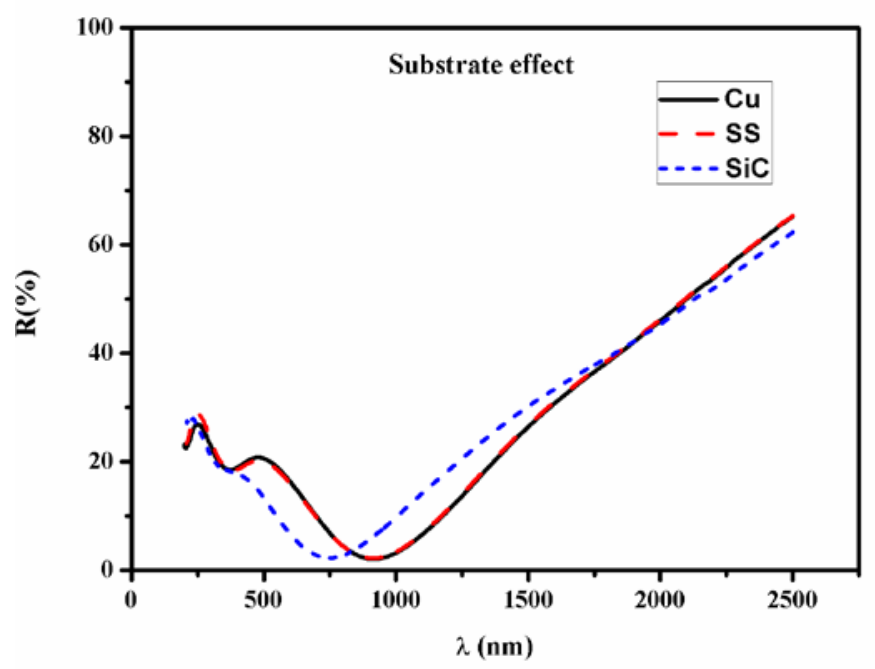

Figure 4. Substrate effect on DLC solar absorber thin films

\section{Optimization of Cr-Metal Layer}

In any solar multi-layer absorber coatings, Cr-metal layer was used as a base reflector. However, optimization of Cr- layer thickness is important factor for multilayer absorber coatings, by using the $\mathrm{Cr}$ cathode currents we can control the thickness of this layer. From the fig.5 clearly observed, the thickness of Cr-layer was 60nm with low Cr-metal concentration in the DLC absorber coating, was not the good absorbance value within the visible region (300nm to $1500 \mathrm{~nm}$ ). After that we have chosen to high Cr-metal concentration, in that Cr-layer with $125 \mathrm{~nm}$ thickens was given good absorbance and low emission within the visible spectra. The optimized Cr- layer has been deposited with 175 A cathode current and $5 \times 10^{-3}$ mbar pressure to achieve a thickness of $125 \mathrm{~nm}$. 


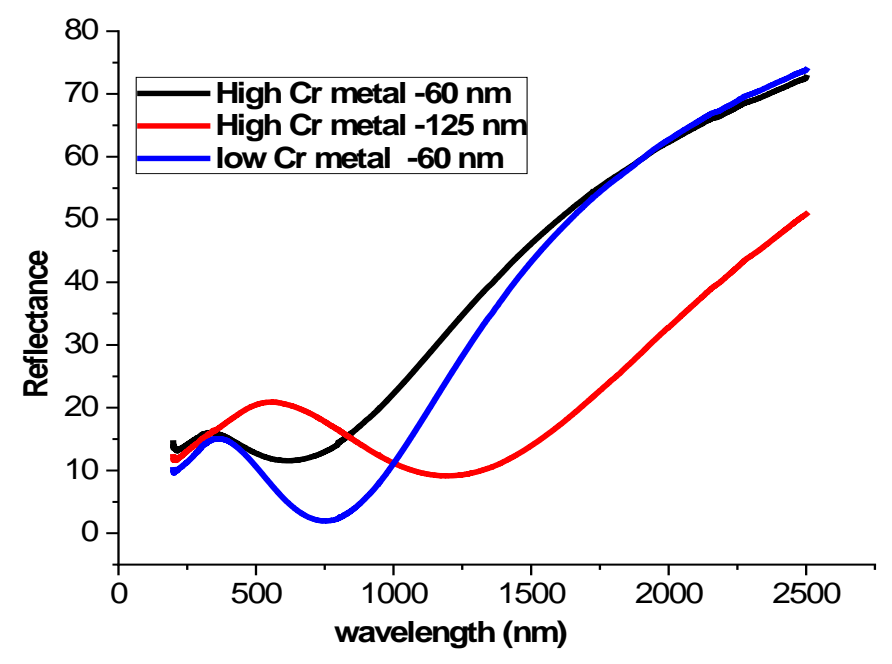

Figure 5. Reflectance spectra of Cr-layer with thickness variation

\section{Optimization of DLC Layer Thickness}

Similar to any other absorber coating, the optical properties of DLC coatings were also expected to depend largely on layer thickness. Hence, the optimization of thickness has been carried out. The results show that the films with $90 \mathrm{~nm}$ thickness have shown better properties. The reflectance spectra of DLC coatings with thickness were shown in Fig. 6, for identifying of better DLC coating thickness we did several experiments. in which we can clearly observed that in the below graph from 300 to $2500 \mathrm{~nm}$ wavelength (this is the visible spectra), the thickness of the DLC coating is $60 \mathrm{~nm}$ then the absorbance $(\alpha-87 \%)$ and emission $(\varepsilon-5 \%)$, this is the first trail. after $1^{\text {st }}$ trail, we increased in thickness of DLC coating $90 \mathrm{~nm}$ then $\alpha-92 \%$ and $\varepsilon-8 \%$, further increased to $120 \mathrm{~nm}$ thickness then the $\alpha-81 \%$ and $\varepsilon-7 \%$. From all this experiments, the thickness of DLC coating is optimize to $90 \mathrm{~nm}$ (where as absorbance value is high as compared to remaining thicknesses).

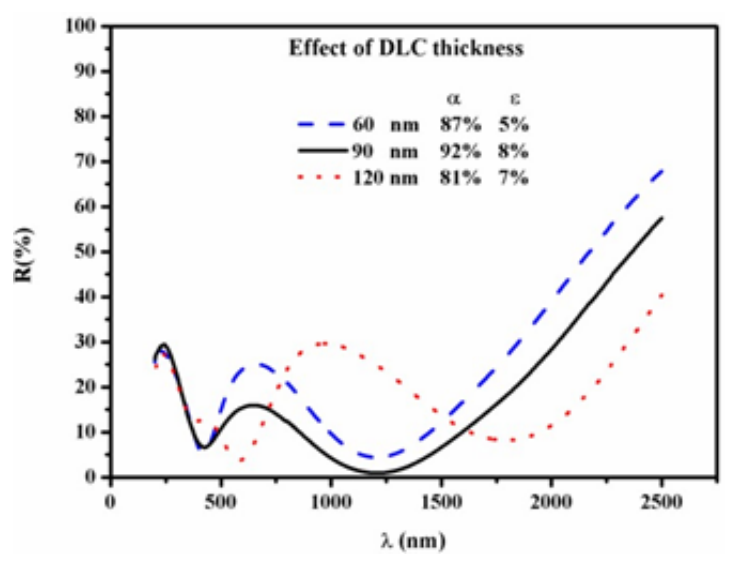

Figure 6. Reflectance spectra of DLC absorber with thickness

\section{Deposition Temperature Optimization}

From literature, it was noted that, the substrate temperature during DLC deposition also influences the optical properties. Hence, the DLC coatings were grown at different substrate temperatures in order to study its effect on optical properties. The effect of substrate temperature on DLC optical properties was shown in Fig. 7.From this graph clearly known that when we go for high temperature $\left(425^{\circ} \mathrm{C}\right)$, than the absorbance value $(\alpha-90 \%)$ slightly 
decreased, if we go below temperature $\left(325^{\circ} \mathrm{C}\right)$, absorbance value $(\alpha-85.8 \%)$ is almost decreased and finally optimized temperature $\left(275^{\circ} \mathrm{C}\right)$ then the absorbance value is almost $(\alpha-92 \%)$ and emission value $(\varepsilon-8 \%)$ is also considerable

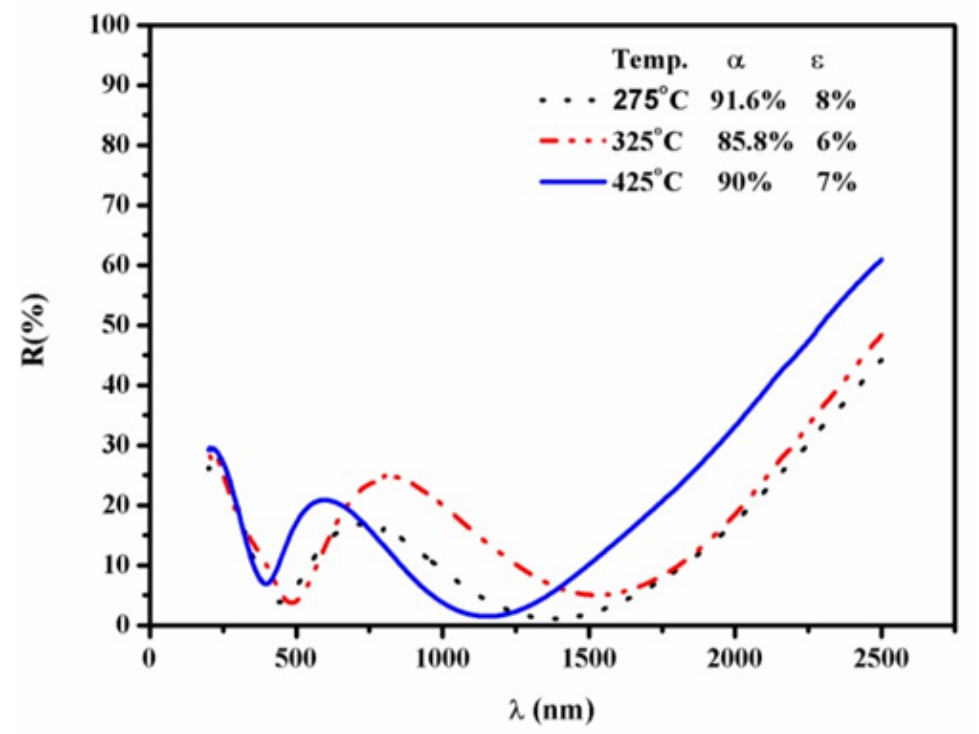

Figure 7. Reflectance spectra of DLC coatings grown at different substrate temperatures

\section{AISiN Layer Thickness Optimization}

Many reports suggested the usage of AlSi anti-reflective layer for the solar selective multilayer coatings. The influence of AlSiN layer thickness (10, 20 and $35 \mathrm{~nm}$ ) on optical absorption and thermal emission of DLC contained multilayer absorber coating was studied. Form the Fig. 8.we clearly absorbed that thickness of the AlSi is $10 \mathrm{~nm}$ and then the required absorbance $(\alpha-91.6 \%)$ is not up to the mark, so thickness of the AlSi layer is increased to $20 \mathrm{~nm}$ then the absorbance value (89.6\%) is decreased. Finally the optimized AlSi layer thickness is $35 \mathrm{~nm}$, then the value of absorbance (92\%) is very good value at $35 \mathrm{~nm}$ thickness. In the graph clearly observed that from $1000 \mathrm{~nm}$ to $1500 \mathrm{~nm}$ pick of the line is down to x-axis (very low reflectance) i.e. absorbance is high. That wavelength range is required visible spectra.

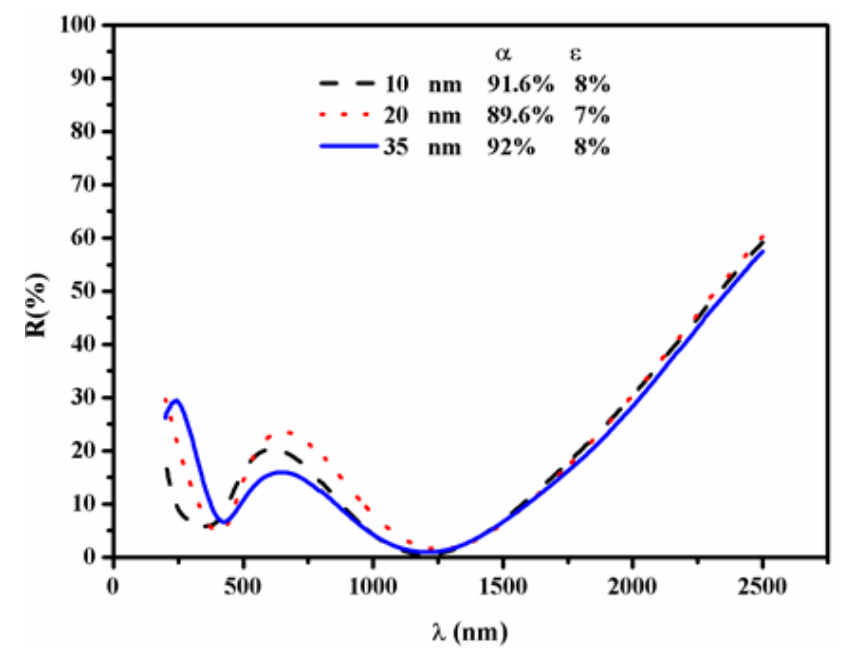

Figure 8. Reflectance spectra of AlSiN layer with thickness variation 
In DLC multilayer absorber coatings, AlSi acts as ananti-reflective layerit is the last layer of the DLC multilayer absorber coating, in these deposition parameters are very important to optimize the good absorbance value. The deposition parameters are shown in table 4.

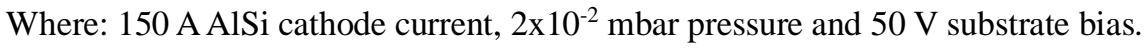

Table 4. AlSiN Deposition parameters

\begin{tabular}{|c|c|}
\hline Base pressure & $1 * 10^{-5} \mathrm{mbar}$ \\
\hline Working pressure & $2 * 10^{-2} \mathrm{mbar}$ \\
\hline AlSi current & $150 \mathrm{~A}$ \\
\hline Mode of operation & Dc mode \\
\hline Bias & $-50 \mathrm{v}$ \\
\hline
\end{tabular}

\section{TEM Image (AlSiN)}

A TEM image of AlSiN shows that it consists of two phases AlN and $\mathrm{Si}_{3} \mathrm{~N}_{4}$.It is found that AlSiN form a Nano- composite structure with AIN as crystalline phase and $\mathrm{Si}_{3} \mathrm{~N}_{4}$ as an amorphous phase. It is evident from TEM picture and is shown in fig.9.This AlSiN layer acts as an anti-reflective coating for DLC multilayer absorber coatings.

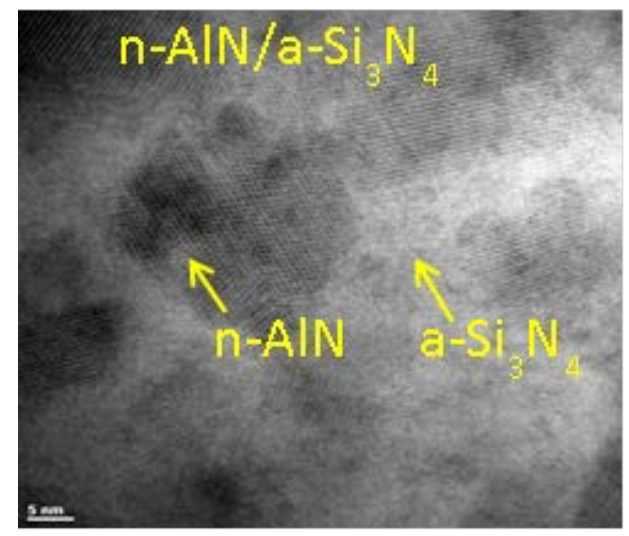

Figure 9. TEM picture of AlSiN

\section{Optimized DLC Based Solar Absorber Coating}

From Fig.10, after all initial optimization experiments (related to individual layers), the overall $\mathrm{Cr} / \mathrm{DLC} / \mathrm{AlSiN}$ multilayer has been optimized by varying overall thickness of the coating. In the optimized multilayer stack, the Cr- layer has been deposited with $175 \mathrm{~A}$ cathode current and $5 \times 10^{-3}$ mbar pressure to achieve a thickness of $125 \mathrm{~nm}$. the individual DLC layer thickness is $90 \mathrm{~nm}$ and upper AlSi layer acts as a anti-reflective then the thickness is $35 \mathrm{~nm}$.all this stack of DLC multilayer absorber coating exhibited highest absorption (0.92) and emission (0.08) with in the required visible region of solar spectra(300nm to $1500 \mathrm{~nm})$. 


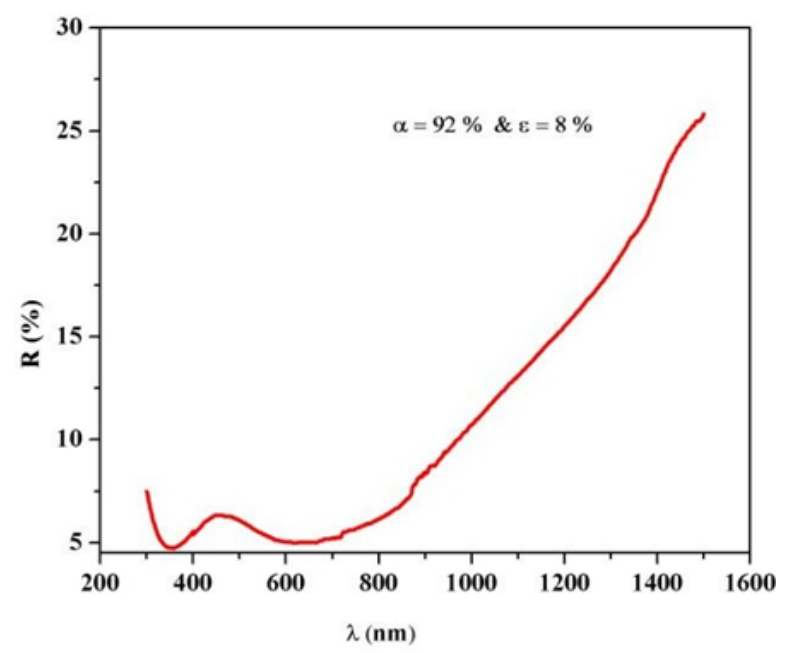

Figure 10. Optimized DLC contained multilayer solar absorber

\section{Morphology and Composition Analysis of DLC}

The surface morphology of DLC coating was shown in Fig. 11. The surface was found to be very smooth with few $\mathrm{Cr}$ macro droplets (white spots shown on the micrograph). It consists of 93.67 atomic \% carbon and 6.33 atomic \% chromium.

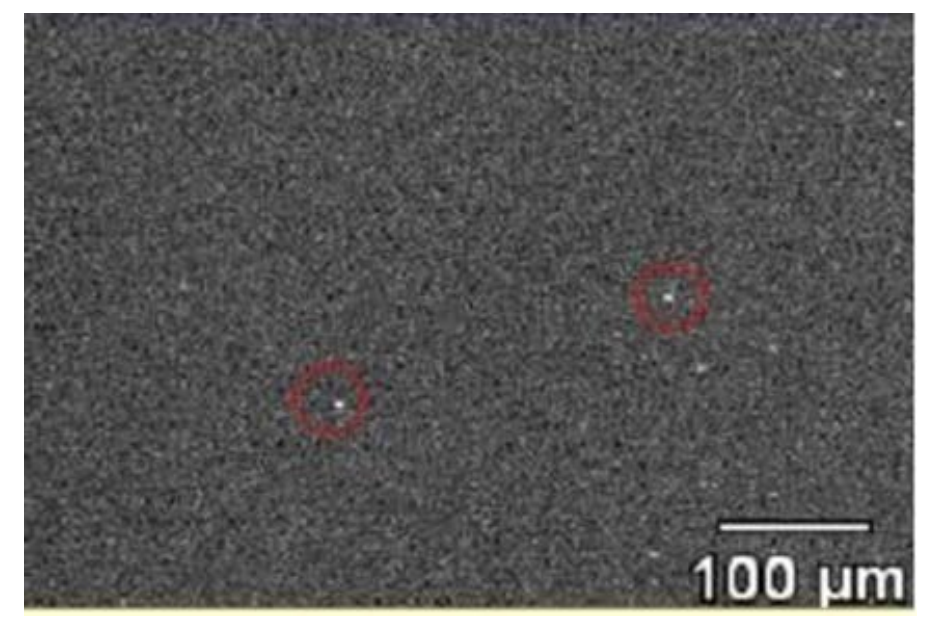

Figure 11. SEM image of DLC multilayer solar absorber coating

\section{Raman Studies}

Diamond like carbon (DLC) has two crystalline forms, graphite (three fold - coordination symmetry) and diamond (four-fold coordination symmetry).The first -order Raman spectra of diamond will have a single line at $1353 \mathrm{~cm}^{-1}$ corresponding to D band. Whereas, the first -order Raman spectra of graphite will have a single line at $1577 \mathrm{~cm}^{-1}$ (corresponds to the G-band at about). In this line, in view of identifying the nature of DLC based absorber coatings, all the coatings were analyzed using Raman studies. The Raman spectra corresponding to optimized DLC layer is shown in Fig. 12. The Raman spectra clearly indicates the presence of both diamond and graphite crystalline forms. 


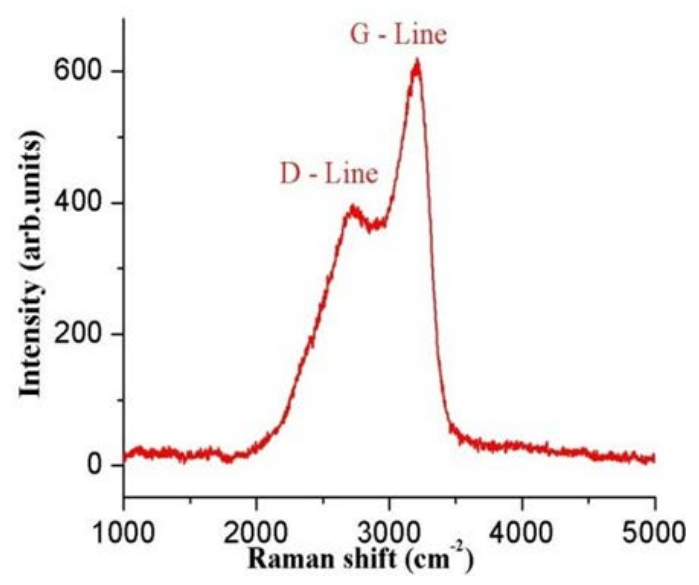

Figure 12. Raman spectrum of optimized DLC thin film

\section{Scratch Resistance Studies}

Using scratch test, determined the adhesion of the coatings. A CSM REVETEST ${ }^{\circledR}$ Scratch Testing instrument equipped with a Rockwell Z-277 indenter $(200 \mu \mathrm{m})$ was used to measure the adhesion of the coating to the substrate. The indenter tip was calibrated using a TiN coated standard sample at a starting load of $0.90 \mathrm{~N}$ progressing to a final load of $175 \mathrm{~N}$. Common methods such as pencil scratch test and cross cut test has been used to calculate adhesion of solar selective coatings. CAPVD developed coatings are known to display excellent substratecoating adhesion, therefore it is impractical to employ the above test methods. The typical scratch profile is shown in Fig. 13. The scratch parameters, begin load, end load, loading rate, critical load1 and critical load2 were shown in table 5.

Table 5. Scratch resistance of multilayer solar absorber coating

\begin{tabular}{|c|c|c|c|c|c|}
\hline $\begin{array}{c}\text { S.N } \\
\text { o }\end{array}$ & $\begin{array}{c}\text { Begin } \\
\text { Load(N) }\end{array}$ & End Load(N) & $\begin{array}{c}\text { Loading } \\
\text { rate(N/min) }\end{array}$ & Lc 1 & Lc 2 \\
\hline 1 & 0.9 & 175 & 435.25 & 21.5 & 48.59 \\
\hline 2 & 0.9 & 60 & 147.75 & 13.85 & 43.94 \\
\hline
\end{tabular}

Where;

Lc-1: critical load 1 where initial crack initiates and

Lc-2: critical load 2 where complete delamination of the film occurs.

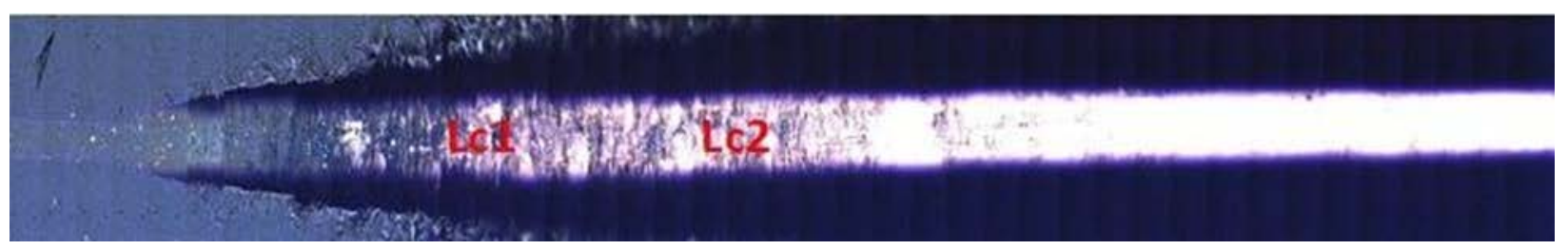

Figure 13. The scratch profile of a $4 \mathrm{~mm}$ scratch taken over DLC solar selective coating

From the fig 13, observed that when we give maximum load was $175 \mathrm{~N}$ with loading rate $435.25 \mathrm{~N} / \mathrm{min}$ then the initial crack was occurred (LC1) at $25 \mathrm{~N}$ and complete delamination (LC2)was occurred at $48.59 \mathrm{~N}$, finally we can clearly say that adhesion strength of the DLC multilayer absorber coating is very good it can withstand approximately 50N. 


\section{Salt Fog Corrosion Test}

Corrosion properties of the developed solar absorber thin film has been studied (as shown in fig 14) by salt fog test ( $5 \% \mathrm{NaCl}$ solution) for 21 days. No corrosion was observed for first 3 days. Later mild corrosion has picked up without much damage to the coating on the $19^{\text {th }}$ day. This salt corrosion test has also given very good values for the DLC multi-layer absorber coatings.

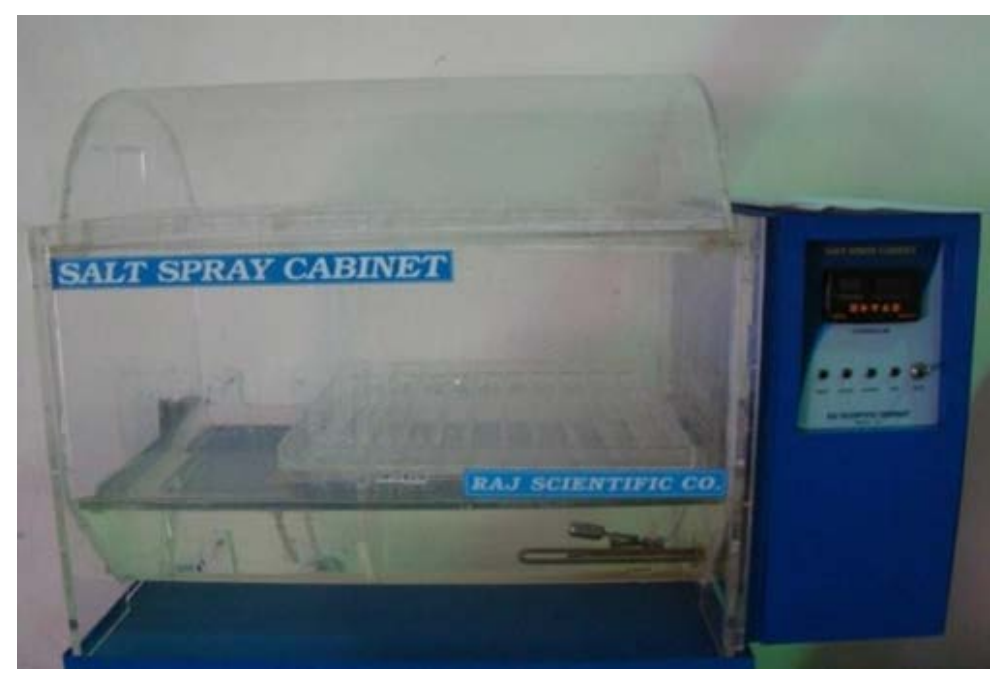

Figure 14. Salt spray chamber

\section{CONCLUSION}

Spectrally selective solar absorber coating $\mathrm{Cr} / \mathrm{DLC} / \mathrm{AlSiN}$ was deposited on $\mathrm{Cu}$, SS and $\mathrm{SiC}$ substrates using Cathodic arc physical vapour deposition (CAPVD) technique.

- Each layer in the multilayer stack has been optimized by varying the different influencing deposition parameters. Like target currents, thickness of each layer, deposition pressure, deposition temperature, $\mathrm{N}_{2}$ partial pressure concentration, deposition time.l

- Optimized the substrate effect for solar DLC absorber coating, trails were done on the Cu , SiC and SS- 306 substrates. SiC substrate gave the extreme good absorbance and low emission values but it ${ }^{\text {es }}$ brittle in nature and low mechanical strength, so that next trails were done on $\mathrm{Cu}$ and SS-306 substrates, results were matched closely but in mechanical strength wise SS-306 performs good, so SS-3036 has been considered.

- The thickness of each layer was optimized such that, there occurs a destructive interference of reflected light enhancing absorption. With the detailed optimization and understanding of the deposition parameters and multilayer structure.

- First thickness of the Cr- Metal base layer was optimized by using the Cr-Target current $175 \mathrm{~A}$ and thickness was optimised to $125 \mathrm{~nm}$, at this thickness Cr-Metal acts as a good base reflector.

- Optimised the DLC layer with thickness 90nm over the range solar visible spectra 300nm to2500 nm. Finally optimized the AlSiN absorber layer with AlSi-Target current (130A to $175 \mathrm{~A}$ ) and thickness $35 \mathrm{~nm}$.

- The best optical properties were achieved: $\alpha=0.92, \varepsilon=0.08$ for $\mathrm{Cr} / \mathrm{DLC} / \mathrm{AlSiN}$ coating and observed Nano-composite structure formation in the AlSiN layer. The crystalline n-AlN and amorphous a-Si $\mathrm{N}_{4} \mathrm{Nano}$ composite structure formation was confirmed using TEM (fig.9) analysis.

- The coatings has good adherence with a delaminating force of $48.59 \mathrm{~N}$ (LC2) as shown in the table 5.

- The formation of DLC was understood from Raman studies that show sharp peaks at 1353 and $1577 \mathrm{~cm}^{-1}$ (fig.12). Salt spray corrosion test also given good results it withstands up to 175 hrs. For DLC multilayer absorber coatings.

- Finally conclude that all solar multilayer coatings shows good absorbance nearly $94 \%$ and low emission 8\% [5] but those are not up to the chemical and radiation stable, for that, DLC multi-layer absorber coating 
gives good absorbance $(\alpha-0.92)$, low emission $(\varepsilon-0.08)$ and high hardness along with chemical and radiation stable over the optical properties.

$\begin{array}{ll}\text { NOMENCLATURE } & \\ \text { CAPVD } & \text { Cathodic Arc Physical Vapor Deposition } \\ \text { CAD } & \text { Cthodic Arc Deposition } \\ \text { DLC } & \text { Diamond like Carbon Coating } \\ \text { CSP } & \text { Concentrated Solar Power Plant } \\ \text { SEM } & \text { Scanning Electron Microscopy } \\ \text { UV-Vis-NIR } & \text { Ultraviolet Visible Near Infrared Spectroscopy } \\ \text { Spectroscopy } & \\ \text { TEM } & \text { Transmission Electron Microscopy } \\ \text { DC mode } & \text { Direct Current Mode } \\ \alpha & \text { Absorbance } \\ \varepsilon & \text { Emissivity } \\ \mathrm{Cr} & \text { Chromium } \\ \mathrm{TiAlN} & \text { Titanium Aluminium Nitrate AlSiO - Alumina } \\ \mathrm{Pb} & \text { Led } \\ \mathrm{Cu} & \text { Cupper } \\ \mathrm{SS}-306 & \text { Stain less Steel 306 SiC - Silicon Carbide } \\ \mathrm{C}_{2} \mathrm{H}_{2} & \text { Acetylene } \\ \mathrm{N}_{2} & \text { Nitrogen }\end{array}$

\section{REFERENCES}

[1] Granqvist, C. G. Solar energy materials, Applied Physics A, Vol.52, 1991, pp : 83-93.

[2] Harish C. Bharshilia, Prashant kumar, Rajam, K. S., Biswas,A.Structure and optical properties of Ag$\mathrm{Al}_{2} \mathrm{O}_{3}$ nanocermet solar selective coatings prepared using unbalanced magnetron sputtering,Soler Energy Matererials and Soler Cells, Vol.95, 2011, pp: 1707-1715.

[3] Harish C. Barshilia, Selvakuma,N., and Rajam,K.S., Sridhara Rao,D.V., Muraleedharan,K. and Biswas,A. TiAlN/TiAloN/Si $3 \mathrm{~N}_{4}$ TiAlN/TiAloN/Si3N4 tandem absorber for high temperature solar selective applications, Applied Physics Letters, Vol.89, 2006, pp: 191909.

[4] Hutchins, M.G. Selective thin film coatings for the conversion of solar radiation, Surface Technology, Vol.20, 1983, pp: 301-320.

[5] Yin, Y.,Pan, Y., Hang, L. X., Mckenzie, D. R., Bilek,M. M. M., Thin Solid Films, Vol.517, 2009, pp: 16011606.

[6] Kennedy, C. E.Review of Mid- to High-Temperature Solar Selective absorber

[7] Materials, NREL/TP-520-31267, July 2002.

[8] Godinho,V., Philippon,D., Rojas,T. C., Novikova,N. N., Yakovlev, V.A., Vinogradov, E. A., Fernandez, A.,Characterization of $\mathrm{Ti}_{1-\mathrm{x}} \mathrm{Al}_{\mathrm{x}} \mathrm{N}$ coatings eith selective IR reflectivity, Solar Energy, Vol.84, 2010, pp: 1397- 1401.

[9] Qui-Chu Zhang, Recent progress in high-temperature solar selective coatings, Soler Energy Materials and Soler Cells, Vol.62, 2000, pp: 63-74.

[10] Smith, G. B., A. Ben-David, Swift,P.D. Energy-Efficient Optical Coating for Flat Glass, Renewable Energy Vol.22, 2001, pp: 79-84.

[11] Ramezanizadeh, M., et al., "Experimental and Numerical Analysis of a Nano-fluidicThermosyphon HeatExchanger,” Engineering Applications of Computational Fluid Mechanics 13(1): 40-47 2019.

[12] Ghalandari, M., et al., "Numerical Simulat ion of Nano-fluid Flow inside Root Canal," EngineeringApplications of Computational Fluid Mechanics 13 (1): 254-264 2019. $23-4$. 
[13] Hussein, A.K. Applications of nanotechnology in renewable energies-A comprehensive overview and understanding, Renewable and Sustainable Energy Reviews, Vol.42, 2015, pp : 460-476.

[14] Hussein, A.K. , Walunj, A. and Kolsi , L. Applications of nanotechnology to enhance the performance of the direct absorption solar collectors, Journal of Thermal Engineering, Vol. 2 , No. 1, 2016, pp : 529- 540.

[15] Hussein, A.K. Applications of nanotechnology to improve the performance of solar collectors - Recent advances and overview, Renewable and Sustainable Energy Reviews, Vol. 62 , 2016, pp : 767-792.

[16] Farooq,M., Hutchins, M. G. Optical properties of higher and lower refractive index composites in solar selective coatings, Soler Energy Materials and Soler Cells, Vol. 71, 2002, pp: 73-83.

[17] Shuxi Zhao, Ewa Wackelgard.Optimization of solar absorbing three-layer coatings, SolerEnergy Materials and Soler Cells, Vol. 90, 2006, pp: 243-261.

[18] Harish, Barshilia,C., Selvakumar, n., and.Rajam,K.S.Structure and optical properties of pulsed sputter deposited $\mathrm{CrxOy} / \mathrm{Cr} / \mathrm{Cr} 2 \mathrm{O}$ crxoy/Cr/Cr2o3 solar selective coatings, Journal of AppliedPhysics, Vol.103, 2008, pp: 023507.

[19] Kiyoshi Chiba and Shota Kaminishi, Fabrication and Optical Properties of Low-Emissivity Coatings of AlSiN and AgCuNd-Alloy Mutilayer Films on Glass, Japanees Journal of Applied Physics, Vol.47, 2008, pp: 1.

[20] Qui Zhang, Direct current magnetron sputtered W-AIN cermet solar absorber films, Journal of Vacuum Science and Technology A, Vol. 151997, pp: 6.

[21] Miao Du, Lei Hao, Jing Mi, Fang Lv, Xiaopeng Liu, Lijun Jiang, Shumao Wang, Optimization design of Tio.5Alo.5N/Tio.25Alo.75N/Aln coating used for solar selective applications, SolerEnergy Materials and Soler Cells, Vol.95, 2011, pp: 1193-1196.

[22] Klyui,N. I., Litovchenko,V. G., Rozhin, A. G., Dikusha,V. N., Kittler,M., and Seifert,W.High efficient solar cells and modules based on diamond like carbon film-multicrystalline Si structures, SolerEnergy Materials and Soler Cells, Vol.72, 2002, pp: 597-603.

[23] Tinchev, S. S., Nikolova, P. I., Dyulgerska, J. T., Danev,G., and Tz. Babeva, a-C:H absorber layer for solar cells matched to solar spectrum, Soler Energy Materials and Soler Cells, Vol.86, 2005, pp: 421- 426.

[24] Gampp,R., Oelhafen, P., Gantenbein,P., Brunold, S., and Frei,U. SolerEnergy Materials and Soler Cells Vol.54, 1998, pp: 369-377.

[25] Tinchev,S. S., Nikolova, P. I. and Dyulgerska,Y. T.Thermal solar absorber made of diamond-like carbon thin films, Journal of Physics, Vol.223, 2010, pp: 012017.

[26] Lespade,P. Al-Jishi,R. and Dresselhaus,M. S.Model for Rman scattering from incompletely graphitized carbons, Carbon, Vol.20, 1982, pp: 427.

[27] Vidano, R. And Fishbach,D. B. New lines in the Raman Spectra of Carbons and Graphite, Journal of American Ceramic Society, Vol.61, 1978, pp: 13.

[28] Chain,E. E., Carver,C. E. and Seraphin,B. O. Highly reflecting molybdenum thin films having significant solar absorptance, Thin Solid Films, Vol.72, 1980, pp: 59.

[29] Gogna,P. K. and Chopra, K. L. Selective black nickel coatings on zinc surfaces by chemical conversion, Soler Energy, Vol.23, 1979, pp: 405.

[30] McDonald,G. E. Spectral reflectance properties of black chrome for use as a solar selective coating, Soler Energy, Vol.17, 1975, pp: 119.

[31] Driver, P. M., Jones,R. W., Riddeford,C. L. and Simpson, R. J.A new chrome black selective absorbing surface, Soler Energy, Vol.19, 1977, pp: 301.

[32] Williams, W. S., Lappin,T. A. and Duffie,J. A. Selective radiation properties of particular coatings, Journal Engineering of Power, Vol.85, 1963, pp: 213.

[33] Electric Power Research Institute, 1997, Renewable Energy Technology Characterizations, Tropical Report No. 109496, Palo Alto CA

[34] Blickensderfer, R., Deardorff,D. K. and L0 Lincoln, R. Spectral reflectance of TiN and ZrNx films as selective solar absorbers, Soler Energy, Vol.19, 1977, pp: 429. 
[35] Choudhury,C. and Sehgal, H. K.Black cobalt selective coatings by spray pyrolysis for photothermal conversion of solar energy, Soler Energy, Vol.28, 1982, pp: 25.

[36] Fan,J. C. C. and Zavracky,P. M. Selective black absorbers using MgO/Au cermet films, Applied Physics Letters, Vol.29, 1976, pp: 478.

[37] Peterson, R. E. And Ramsey,J. W. Thin film coatings in solar thermal power systems, Journal of Vacuum Science and Technology, Vol.12, 1975, pp: 174.

[38] Fan, J. C. C. and Bachner,F. J. Transparent heat mirrors for solar energy applications, Applied Optics, Vol.15, 1976, pp: 1012.

[39] Schmidt,R. N., and Park,K. C. High temperature space-stable selective solar absorber coatings, Applied Optics, Vol.4, 1965, pp: 91. 